\title{
Educação Popular no Ensino Superior: um diálogo entre a Universidade de Évora e o Alentejo ${ }^{1}$
}

\author{
Bravo Nico \& Lurdes Pratas Nico \\ Universidade Popular Túlio Espanca/Universidade de Évora \\ jbn@uevora.pt / lpnico@uevora.pt
}

\begin{abstract}
Resumo: Em 2009, a Universidade de Évora criou a Universidade Popular Túlio Espanca (UPTE/UÉ), no sentido de aumentar a sua interação com a região em que se encontra localizada (Alentejo), aproveitando o seu potencial cultural, científico e tecnológico e mobilizando os seus recursos humanos. Desde essa data, a UPTE/UÉ tem vindo a concretizar um projeto educativo assente na criação e disponibilização de atividades educativas em contextos não formais de aprendizagem, nos quais ocorre um encontro entre a comunidade académica e a comunidade local e entre os conhecimentos científicos e os saberes experienciais, numa abordagem que enriquece todos os participantes. Paralelamente, tem vindo a ser instituída uma rede regional de educação popular, através da criação de polos da UPTE/UÉ no Alentejo.
\end{abstract}

Palavras-Chave: Ensino Superior, Educação Popular, Extensão Universitária

\section{INTRODUÇÃO}

A Universidade Popular Túlio Espanca/Universidade de Évora (UPTE/UÉ) existe, formalmente, desde 2009 e tem vindo a contribuir para a concretização do trabalho de extensão universitária da academia eborense.

Assumidamente uma escola popular e presente no território da região Alentejo, através de uma rede de polos (Alandroal, Canaviais, Portel e Viana do Alentejo e a Escola Comunitária de São Miguel de Machede, como parceira, desde a sua fundação), a UPTE/UÉ recorre aos recursos científicos, culturais, físicos, tecnológicos e humanos da academia e aos recursos dos seus parceiros locais, nos quais se incluem as autarquias locais e organizações da sociedade civil.

A rede de educação popular, entretanto constituída no território alentejano, tem vindo a promover projetos educacionais de diferentes formatos didáticos e dirigidos a diferentes públicos, de acordo com a forma, autónoma como cada polo concretiza as suas finalidades. Nos últimos dois anos - no âmbito do projeto «Janelas Curriculares de Educação Popular no Ensino Superior Universitário», que tem vindo a ser promovido pela Universidade Popular Túlio Espanca e financiado pela Fundação Calouste Gulbenkian, no âmbito do Programa

\footnotetext{
${ }^{1}$ Comunicação decorrente da concretização do projeto «Janelas Curriculares de Educação Popular no Ensino Universitário» promovido pela Universidade Popular Túlio Espanca/Universidade de Évora e financiado pela Fundação Calouste Gulbenkian, no âmbito do Programa Gulbenkian Qualificação das Novas Gerações/Projetos de Desenvolvimento do Ensino Superior/Projetos Inovadores no Domínio Educativo/ 2014
} 
Gulbenkian Qualificação das Novas Gerações/Projetos de Desenvolvimento do Ensino Superior -, a academia tem iniciado um processo de incorporação da educação popular no contexto curricular dos planos de estudo de alguns estudantes, com a supervisão dos seus docentes. Neste contexto, algumas atividades de aprendizagem concretizadas pelos estudantes são transformadas e valorizadas, em determinadas circunstâncias, em oportunidades de educação popular abertas à participação de todos.

\section{A UPTE/UÉ NO QUADRO INSTITUCIONAL DA UNIVERSIDADE DE ÉVORA}

A Universidade Popular Túlio Espanca (UPTE/UÉ) foi, desde a sua fundação, considerada uma unidade científica e pedagógica da Universidade de Évora, tendo-lhe sido atribuída a missão de garantir, aos cidadãos da região Alentejo, oportunidades diversificadas de formação ao longo da vida, no âmbito da estratégia de entrosamento da Universidade com a sociedade envolvente.

Num primeiro período da sua existência, este projeto da Universidade de Évora teve a designação de Universidade Sénior Túlio Espanca. No entanto, atendendo ao perímetro conceptual assumido (educação popular de perfil intergeracional e concretizada em contextos não formais de aprendizagem), desde muito cedo que o termo popular ficou associado à designação oficial. Em 2016, aquando da última revisão estatutária, a designação atual ficou consagrada, formalmente, nos Estatutos da Universidade de Évora. Este facto, mais do que uma mera questão de nomenclatura, foi uma consequência de um percurso realizado, no qual, o modelo pedagógico assente na educação não formal de perfil intergeracional se revelou como a mais adequada solução pedagógica e organizacional para um projeto que pretende concretizar o princípio comeniano de ensinar tudo a todos, de todas as maneiras possíveis.

A UPTE/UÉ possui um diretor e uma pequena equipa técnica constituída por docentes, discentes e funcionários não docentes da Universidade que, em regime de voluntariado, exercem funções de direção e coordenação técnica, no âmbito dos diferentes projetos promovidos. Os recursos financeiros necessários para o funcionamento da UPTE/UÉ são conseguidos através de candidaturas sucedidas de projetos e com o recurso à rede de parceiros que, entretanto, se foi constituindo, no território alentejano.

Os docentes, investigadores, discentes e funcionários não docentes da Universidade de Évora são convidados a participar na dinâmica da UPTE/UÉ, através da apresentação de propostas de projetos e atividades ou da sua participação nos que se encontram em 
execução. Todas as participações decorrem voluntariamente, sem que delas resulte qualquer remuneração ou evidência que possa ser considerada na avaliação de desempenho.

\section{A UPTE/UÉ NO QUADRO DAS RELAÇÕES DA UNIVERSIDDE DE ÉVORA COM O ALENTEJO}

A Universidade Popular Túlio Espanca (UPTE/UÉ) é, no presente, uma rede regional de educação popular que conta com cinco polos: Alandroal, Canaviais/Évora, Portel, São Miguel de Machede/Évora e Viana do Alentejo. Esta rede tem vindo a ser construída, de forma sustentável, contando com o envolvimento de instituições locais de referência na vida das comunidades:

1. No que se refere ao polo de São Miguel de Machede, a parceria estabeleceu-se com a Escola Comunitária local/SUÃO-Associação de Desenvolvimento Comunitário, no momento da fundação da UPTE/UÉ, em 2009.

2. Em 2010, foram instituídos os polos de Alandroal e Viana do Alentejo, numa parceria que envolveu, diretamente, os municípios respetivos;

3. Em 2011, foi criado o polo de Portel, nas mesmas condições institucionais dos anteriores;

4. Em 2016, abriu o polo de Canaviais (freguesia periurbana do concelho de Évora), numa parceria que envolveu a Junta de Freguesia e a Casa do Povo locais.

Em cada um dos cinco polos, existe um projeto educativo próprio e distinto dos restantes, construído com total autonomia, suportado por uma equipa técnica e pedagógica local e assente numa rede territorializada de parceiros. No entanto, em cada ano letivo, são articulados os diferentes planeamentos educativos no sentido de se rentabilizarem os recursos existentes na rede e se construírem projetos e atividades que possam envolver participantes de todos os polos e contar com o contributo de membros da academia universitária.

Ao longo do tempo, o trabalho de articulação dos diferentes projetos educativos tem vindo a aprofundar-se e, na atualidade, ocorre já um número significativo de atividades com a presença simultânea de participantes de toda a rede. Estas atividades também são distribuídas pelos polos, de forma uniforme.

No último ano letivo (2015/2016), foram definidos, por todos os parceiros, alguns princípios pedagógicos e organizacionais que promovem alguma uniformização no que 
respeita à tipologia de atividades a concretizar, abordagens didáticas preferenciais e tipo de certificação a disponibilizar aos participantes.

\section{O MODELO PEDAGÓGICO DA UPTE/UÉ}

A Universidade Popular Túlio Espanca (UPTE/UÉ) assumiu, desde a sua fundação e como já foi referido, um modelo pedagógico assente na educação popular de matriz perfil intergeracional e concretizada em contextos não formais de aprendizagem (Nico, 2006) que consideram e valorizam o território e os recursos nele disponíveis, como um elemento curricular fundamental (D’Órey \& Nico, 2004). Esta moldura conceptual traduziu-se, na realidade concreta, da seguinte forma:

1. Qualquer pessoa pode participar em qualquer atividade promovida pela UPTE/UÉ, independentemente da idade, nível de escolaridade, situação profissional ou qualquer outra circunstância pessoal. A participação apenas fica condicionada a qualquer limitação operacional na concretização das atividades educativas;

2. As atividades educativas da UPTE/UÉ não conferem certificação formal com relevância ou equivalência académica e/ou profissional. No entanto, a participação em qualquer projeto ou atividade da UPTE/UÉ proporciona, aos participantes, um certificado com informação detalhada acerca da aprendizagem concretizada e das condições em que tal se verificou;

3. Privilegiam-se os projetos e atividades que promovam, intencionalmente, a presença e participação simultâneas de pessoas de diferentes idades e distintos níveis de escolaridade, no sentido da concretização de aprendizagens que fomentem a cooperação intergeracional e que mobilizem e valorizem distintos saberes e diferentes percursos de vida;

As atividades educativas desenvolvidas na UPTE/UÉ assumem diferentes formatos, destacando-se os seguintes:

1. Cursos Breves: oportunidades de formação de curta duração concebidas e concretizadas, de acordo com interesses e necessidades individuais ou institucionais e adaptadas aos recursos existentes, em cada momento, na Universidade de Évora e nas instituições parceiras, caso existam;

2. Ações Singulares: oportunidades de aprendizagem de cariz pontual, que assumem vários formatos (Palestras, Conferências, Seminários, Mesas-Redondas, etc.); 
3. Visitas De Estudo: oportunidades de aprendizagem que pressupõem a deslocação dos participantes a um determinado local. As visitas de estudo poderão ocorrer dentro da própria Universidade de Évora ou no seu exterior;

4. Janelas Curriculares de Educação Popular: episódios de educação popular de perfil não formal e intergeracional desenhados e concretizados no seio dos planos de estudo curriculares disponibilizados pela Universidade de Évora, no âmbito da sua oferta formativa regular. Estas atividades são previamente negociadas e definidas pelos docentes e discentes, nas unidades curriculares em que as mesmas ocorrem, e oportunamente divulgadas, no âmbito do projeto educativo da UPTE/UÉ, para cada ano letivo (Nico et al, 2015a; Nico et al, 2015b);

5. Outros Formatos: dispositivos de formação com geometria funcional e temporal diversificada, sempre que as circunstâncias o aconselhem e as condições o permitam. (cf. www.utulioespanca.uevora.pt).

Nos últimos dois anos, a UPTE/UÉ desenvolveu um projeto inovador no ensino superior português denominado "Janelas Curriculares de Educação Popular no Ensino Superior Universitário”, financiado pela Fundação Calouste Gulbenkian, no âmbito do Concurso de Projetos Inovadores no Domínio Educativo /Desenvolvimento do Ensino Superior/Programa Gulbenkian Qualificação das Novas Gerações 2014.

O objetivo geral do projeto consiste em proporcionar, aos estudantes da academia, oportunidades de desenhar e materializar projetos de educação não formal abertos à participação da população da região e que mobilizem e valorizem o conhecimento e as competências científica, cultural, técnica e tecnológica presentes nas suas formações académica e articulados, sempre que possível, pelos docentes das unidades curriculares que frequentam (Nico \& Nico, 2016).

O projeto parte ainda do princípio de que é vantajoso, para a qualidade das aprendizagens, a substituição de alguns instrumentos didáticos e de avaliação por projetos de divulgação e promoção científicas, nos quais os estudantes se envolvem mobilizando e aplicando, em contexto de educação popular, os conhecimentos e as competências edificados na academia. Esta experiência pericurricular enriquecerá o curriculum vitae dos estudantes participantes, com competências sociais sempre muito valorizadas em futuros contextos profissionais e que podem aumentar a sua motivação presente (Nico, 2013), uma vez que conferem utilidade social ao conhecimento académico. 


\section{ALGUNS RESULTADOS DA UPTE/UÉ}

Ao longo dos 7 anos de funcionamento da UPTE/UÉ, há algumas evidências que suportam uma avaliação positiva do seu contributo para o diálogo entre a Universidade de Évora e o Alentejo:

i) Foram abertas 6 novas escolas (Évora, Canaviais, Alandroal, Portel, Viana do Alentejo e São Miguel de Machede) numa região em que encerraram, na última década, centenas de escolas;

ii) Cerca de um milhar de pessoas participa, com alguma regularidade, em atividades de educação popular, na rede existente;

iii) O número de membros da academia, participantes em atividades da UPTE/UÉ, tem vindo a crescer, de forma lenta mas consolidada, o que revela uma base importante de trabalho e uma grande margem de crescimento interna para o projeto;

iv) O reconhecimento social do projeto é crescente, devido, em parte, ao papel do Diário do SUL (um jornal regional que é parceiro fundador), na divulgação pública da atividade da UPTE/UÉ, e à capacidade que esta tem revelado, ao conseguir financiamentos para os seus projetos, em programas de instituições de referência.

\section{REFERÊNCIAS BIBLIOGRÁFICAS}

D’Orey, J. \& Nico, B. (2004). Gestão curricular local: fundamento para a promoção da literacia científica. in Bravo Nico et al. Aprender no Alentejo - II Encontro Regional de Educação. Évora: Departamento de Pedagogia e Educação da Universidade de Évora. pp. 111-115.

Nico, B. (2006). Práticas Educativas e Aprendizagens Formais e Informais: encontros entre cidade, escola e formação de Professores. in Inês Bragança et al (Orgs.) Vozes da Educação: Memórias, histórias e formação de professores. Petrópolis: DP et Alii Editora Ltda. pp. 197-206.

Nico, B. (2013). Passado e Futuro no Presente dos Percursos de Qualificação: A Equação da Aprendizagem. in Elisa Chaleta et al (Orgs). Atas da II International Conference Learning and Teaching in Higher Education/ Learning Orchestration in Higher Education. Évora: Universidade de Évora. pp. 312-317.

Nico, B., Nico, L., Tobias, A., Barnabé, J. (2015a). Universidade Popular Túlio Espanca (UPTE): o encontro entre a Universidade de Évora, a Educação não Formal e o Alentejo. Revista de Estudios e Investigación en Psicología Y Educación, vol. Extra, (5) 29-32.

Nico, B., Nico, L., Tobias, A., Barnabé, J., Ramalho, P. \& Lopes, D. (2015b). Janelas Curriculares de Educação Popular na Universidade de Évora: dar utilidade social ao conhecimento académico. Revista de Estudios e Investigación en Psicología Y Educación, vol. Extra, (5) pp. 33-37. 